\title{
Central corneal thickness of Iraqi population in relation to age, gender, refractive errors, and corneal curvature: a hospital-based cross-sectional study
}

\author{
This article was published in the following Dove Press journal: \\ Clinical Ophthalmology \\ 25 November 2016 \\ Number of times this article has been viewed
}

\section{Yasir Jawad Kadhim' \\ Qasim K Farhood ${ }^{2}$}

'Ibn Al Haitham Teaching Eye Hospital, Baghdad, ${ }^{2}$ Department of Ophthalmology, College of Medicine, University of Babylon, Babylon, Iraq
Correspondence: Qasim K Farhood Department of Ophthalmology, College of Medicine, University of Babylon, Babylon, 5200I, Iraq Tel +964 780 II 9098 Email qasim_1964@ymail.com
Background: Central corneal thickness (CCT) is an important indicator of corneal status. Its measurement provides valid information about corneal physiological condition and possible changes associated with diseases, traumas, and hypoxia. It is an integral part for interpretation of intraocular pressure and glaucoma patient management and in prerefractive procedure assessment.

Objective: The aim of this study is to determine the mean CCT among a normal Iraqi population and to correlate between CCT and age, gender, refraction, and corneal curvature.

Patients and methods: This cross-sectional study was carried out at Ibn Al-Haitham Teaching Eye Hospital. A total of 418 eyes from 209 healthy individuals with an age range from 20 to 75 years were studied. CCT was measured by ultrasound pachymeter. Refraction was measured using an auto-refractor and confirmed by trial lenses and retinoscopy to calculate the spherical equivalent. Corneal curvature was measured using an auto-refracto-keratometer to calculate the average corneal curvature (AVK).

Results: The mean CCT was $543.95 \pm 32.58 \mu \mathrm{m}$ with a range from 422 to $636 \mu \mathrm{m}$. CCT was not affected by gender. CCT significantly negatively correlated with age and AVK. CCT significantly positively correlated with the spherical equivalence.

Conclusion and recommendation: Among an Iraqi population, CCT significantly decreased with age. Myopics had significantly thinner corneas. There was weak but significant negative correlation between CCT and corneal curvature. We recommend further studies about the relationship between central corneal thickness and other ocular parameters in Iraqi population such as the axial length.

Keywords: CCT, age, ultrasound pachymeter, gender, refractive errors, corneal curvature

\section{Introduction}

The cornea is a transparent, avascular tissue that measures $11-12 \mathrm{~mm}$ horizontally and 10-11 mm vertically. ${ }^{1}$ The cornea along with sclera forms the outermost coat of the eyeball, it is a complex structure which, as well as having a protective role, is responsible for about three quarters of the optical power of the eye. ${ }^{2}$ It contributes $74 \%$, or 43.25 diopters (D), of the total 58.60 dioptric power of a normal human eye. Its refractive index is $1.376 .{ }^{1}$ The normal cornea is free of blood vessels. ${ }^{2}$ For its nutrition, the cornea depends on glucose diffusing from the aqueous humor and oxygen diffusing through the tear film. In addition, the peripheral cornea is supplied with oxygen from the limbal circulation. The cornea has one of the body's highest densities of nerve endings, and the sensitivity of the cornea is 100 times that of the conjunctiva. ${ }^{1}$ 
The cornea is composed of six layers; which are epithelium, Bowman's layer, stroma, Dua's layer, Descemet's membrane, and endothelium. ${ }^{2,3}$

The corneal epithelium is composed of nonkeratinized, nonsecretory, stratified squamous epithelium, which is 4-6 cell layers thick $(40-50 \mu \mathrm{m}),{ }^{4,5}$ it makes up $~ 5 \%-10 \%$ of the total corneal thickness. ${ }^{1}$

The corneal stroma provides important structural integrity, ${ }^{4,5}$ it makes up $90 \%$ of corneal thickness; it is $\sim 450 \mu \mathrm{m}$ thick in the central cornea. ${ }^{6}$ It is arranged in regularly orientated layers of collagen fibrils whose spacing is maintained by proteoglycan ground substance (chondroitin sulfate and keratin sulfate) with interspersed modified fibroblasts (keratocytes). ${ }^{2}$ Maintenance of the regular arrangement and spacing of the collagen is critical to optical clarity. Transparency also depends on keeping the water content of the corneal stroma at $78 \%$. Corneal hydration is largely controlled by intact epithelial and endothelial barriers and the functioning of the endothelial pump. ${ }^{1}$

The corneal endothelium is made up of closely interdigitated cells arranged in a mosaic pattern of mostly hexagonal shapes. Human endothelial cells do not proliferate, cell density declines throughout life. The corneal endothelium maintains corneal clarity by acting as a barrier to the aqueous humor and by providing a metabolic pump. ${ }^{1}$ Corneas with endothelial cell counts below 500 cells $/ \mathrm{mm}^{2}$ may be at risk for development of corneal edema. ${ }^{4,5}$

Central corneal thickness (CCT) is an important indicator of corneal health status and it is an essential tool in the assessment and management of corneal diseases and helps to estimate the corneal barrier and endothelial pump function. ${ }^{7}$ The determination of corneal thickness has gained relevance in recent years, partly due to the growing interest in the continued use of contact lenses, refractive surgery, and the early identification of those who are at a higher risk of developing primary open angle glaucoma. ${ }^{1}$

Normally, as a diurnal variation, corneas tend to be slightly thicker just after a person awakes in the morning. This increase in thickness is the consequence of diminished evaporation of water from underneath the closed eyelids, and the result of reduced nocturnal metabolic activity of the endothelium. ${ }^{4,5} \mathrm{~A}$ diurnal variation of $10 \mu \mathrm{m}$ for the central thickness and $20 \mu \mathrm{m}$ in the periphery at $40^{\circ}$ was reported by Kiely et al. ${ }^{8}$

Studies have shown that CCT significantly influences the measured intraocular pressure and consequently, the classification and management of glaucoma. ${ }^{9,10}$ Previous studies have demonstrated a positive correlation between CCT and intraocular pressure measured by applanation which causes overestimation of true intraocular pressure in thicker corneas and the converse in thinner ones. ${ }^{11}$

In the planning, refractive, and certain surgical procedure (such as astigmatic keratectomy, laser in situ keratomileusis, photo refractive keratectomy, and Intacs placement), the CCT value is useful for deciding whether a patient should be considered before surgery and which technique would be most adequate. ${ }^{12,13}$ Particularly when performing laser in situ keratomileusis because the amount of correction is limited by the corneal thickness. ${ }^{14}$

Corneal pachymetry is the process of measuring the thickness of the cornea and can be done using contact methods such as ultrasound and confocal microscopy or noncontact methods such as optical biometry with a single Scheimpflug camera (such as the Oculus Pentacam or Sirius), Dual Scheimpflug (eg, Galilei), coherence tomography (Visante, iVue, or others), optical coherence pachymetry (with Orbscan). ${ }^{13}$

Ultrasound pachymetry is easy, portable, and the most widely used method of measuring CCT. ${ }^{4,5}$ Ultrasound pachymetry is usually considered as the main method used to measure CCT, this is because of its relative simplicity and low cost. ${ }^{15}$ The instrument function by measuring the amount of time (transit time) needed for the ultrasound pulse to pass from the end of the Descemet's membrane and back to the transducer. ${ }^{16}$

The aim of the study is to measure the mean central thickness in a sample of normal Iraqi population and to evaluate associations between the CCT and the age, gender, refraction, and corneal curvature.

\section{Materials and methods Study design}

A randomized hospital-based cross-sectional study was carried out during the period from January till the first of April 2016 at Ibn Al Haitham Teaching Eye Hospital in Baghdad. This study was approved by the Scientific Council of Ophthalmology of Iraqi Board for Medical Specialization. The research follows the tenets of the Declaration of Helsinki, and each person gave his or her written informed consent to participate in the study.

\section{Study sample}

A total of 418 eyes from 209 healthy individuals with age range from 20 to 75 years were collected. 


\section{Exclusion criteria}

Excluded from this study were individuals age $<20$ years, eyes with corneal pathology as edema, scarring or corneal dystrophy, contact lens wearing history, eyes with history of refractive or ocular surgery, history of ocular trauma, glaucomatous eyes, and eyes with intraocular pressure $>21 \mathrm{mmHg}$. Patients with systemic disease (such as diabetes or rheumatoid arthritis) and pregnant ladies were also excluded.

The identifying data were the age and gender while the examination data measured in the study were $\mathrm{CCT}$, refraction, and corneal curvature. All measurements were done at the same time of the day, between 9:00 am and 1:00 pm.

CCT was measured by ultrasound pachymeter (SP-3000; Tomey Corporation, Nagoya, Japan); subject was comfortably seated with the head upright and eyes in the primary position of gaze. The probe was sterilized with $70 \%$ alcohol and allowed to air-dry. A drop of topical anesthetic (Tetracaine $\mathrm{HCl} 0.1 \%$ ) was instilled in the subject's eye. The probe was carefully aligned perpendicularly to and lightly applanating the center of the cornea. Five readings in the center are taken and the average calculated as the measured CCT.

Refraction was measured using an autorefractor (RC-5000; Tomey Corporation) and confirmed subjectively by trial lenses and retinoscopy. Refraction was calculated in $\mathrm{D}$ as the spherical equivalent (SE) which equals to spherical refractive error plus $0.5 \times$ cylindrical refractive errors.

The corneal curvature was measured using an autorefracto-keratometry (RC-5000; Tomey Corporation) which measures the two major corneal radii separated by $90^{\circ}$ ( $\mathrm{k} 1$ and $\mathrm{k} 2$ ), and the average of both values was recorded as the average corneal curvature (AVK).

The patients were divided into five age groups (10 years interval). The patients were classified according to refraction into three major groups: emmetropia ( $\mathrm{SE}+0.25 \mathrm{D}$ to $-0.25 \mathrm{D}$ ), myopia ( $\mathrm{SE}<-0.25 \mathrm{D}$ ), and hypermetropia (SE $>+0.25 \mathrm{D}$ ). Then further subclassification of myopia into three groups: mild myopia (myopia $<-3 \mathrm{D}$ ), moderate myopia (myopia from $-3 \mathrm{D}$ to $<-6 \mathrm{D}$ ), and severe myopia (myopia $=$ or $>-6 \mathrm{D}$ ). Hypermetropia subclassified into two groups: mild-moderate hypermetropia $(<+3 \mathrm{D})$ and moderate-severe hypermetropia $(\geq+3 \mathrm{D})$.

\section{Data analysis}

Statistical analysis was performed using SPSS version 20 . Discrete variables presented as numbers and percentages and continuous variables presented as mean \pm standard deviation. Pearson's correlation coefficient was used to test the correlations. Independent sample $t$-test was used to test the mean difference between two independent samples, and analysis of variance test with post hoc Tukey's test for $>2$ independent samples; $P$-value of $<0.05$ was considered statistically significant.

\section{Results}

This study enrolled 209 normal persons in whom both eyes were examined given a total number of examined eyes of 418. Mean CCT for the entire group was $543.95 \pm 32.58 \mu \mathrm{m}$ (range 422 to $636 \mu \mathrm{m}$ ). Mean age of the group was $40.1 \pm 14.6$ years (range $20-75$ years). Mean AVK of the group was $43.44 \pm 1.53 \mathrm{D}$ (range 39.00 to $47.20 \mathrm{D}$ ). Mean $\mathrm{SE}$ of the group was $-1.51 \pm 3.13 \mathrm{D}$ (range +6.00 to $-12.5 \mathrm{D}$ ).

Figure 1 presents the distribution of CCT values for all eyes included in this study.

Table 1 summarizes the data for correlation between CCT and age groups ( $P$-value $<0.001)$. On relating mean CCT to age group, it starts as $553.14 \mu \mathrm{m}$ in the age group 20-29 years and gradually ends as $528.75 \mu \mathrm{m}$ in age $\geq 60$ years; and by comparing its level to the age group 20-29 years, it is observed significantly lower at ages $\geq 40$ years. The difference in mean CCT between the age groups of $20 \mathrm{~s}$ and $30 \mathrm{~s}$ was not significant.

Table 2 showed no significant difference in CCT means between the two genders.

Figure 2 demonstrates the relationship between CCT and $\mathrm{AVK}$, in which there is a statistically significant negative correlation (Pearson $r=-0.097, P=0.048$ ).

Figure 3 demonstrates the relationship between CCT and $\mathrm{SE}$, in which there is a statistically significant positive correlation (Pearson $r=0.153, P=0.002$ ).

Table $3 \mathrm{~A}$ and $\mathrm{B}$ summarizes the data for correlation between CCT and SE classes and subclasses. There is a significant difference in mean CCT between myopic and emmetropic groups $(P$-value $=0.019)$, the myopics had significantly thinner cornea than emmetropics.

Table 4 summarizes the correlations between CCT and study variables (age, AVK, and SE) which shows significant correlations $(P$-value $<0.05)$.

\section{Discussion}

CCT is an important indicator of corneal health status. The measurement of the corneal thickness (pachymetry) is an integral part of a thorough ophthalmic evaluation. CCT determination has become very important for interpretation 


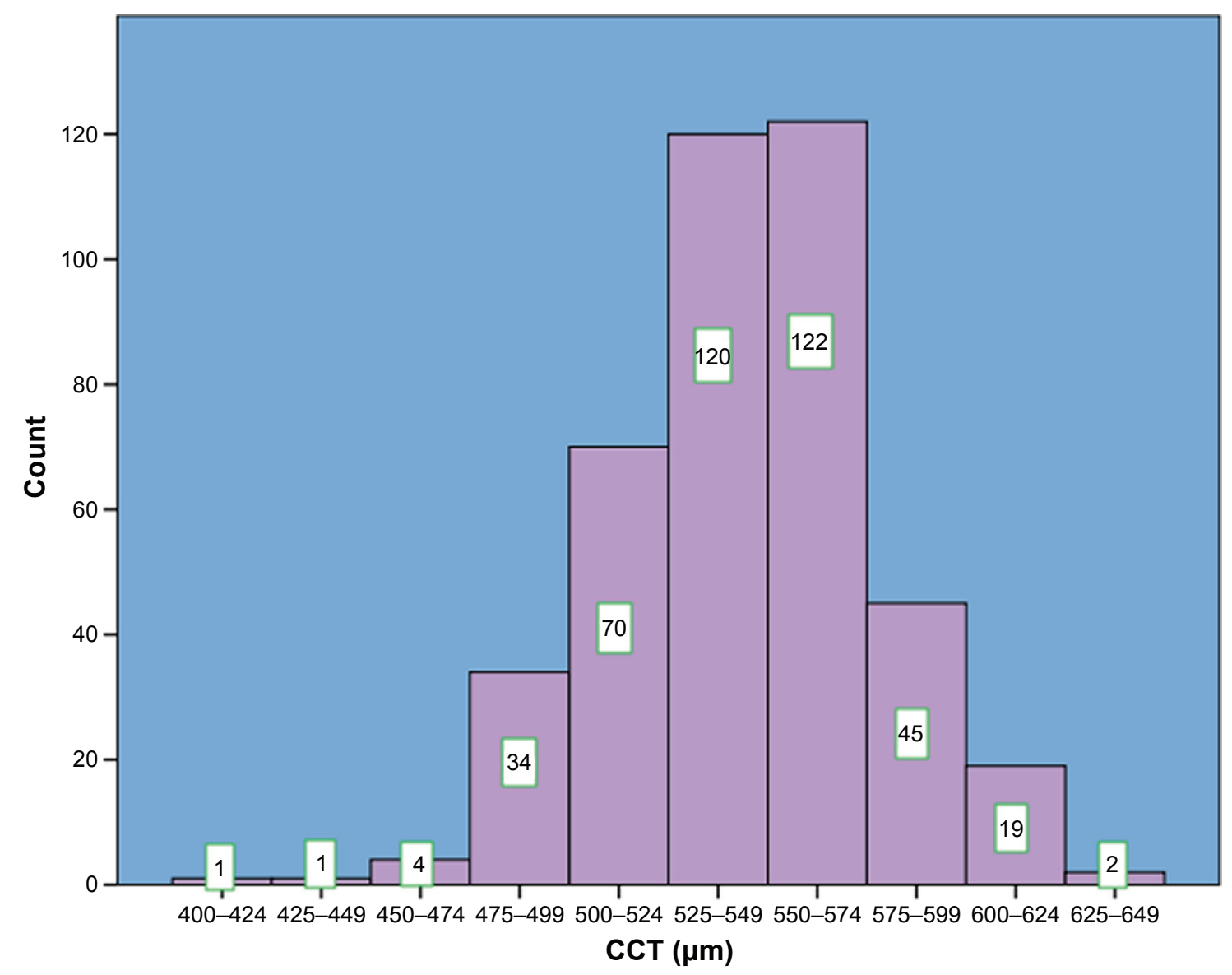

Figure I The distribution of central corneal thickness in the study sample. Abbreviation: CCT, central corneal thickness.

Table I Descriptive statistics for CCT according to age group

\begin{tabular}{|c|c|c|c|c|c|c|c|c|}
\hline \multirow[t]{2}{*}{ Age group } & \multirow{2}{*}{$\begin{array}{l}\text { Number } \\
\text { of patients }\end{array}$} & \multirow[t]{2}{*}{$\%$} & \multirow{2}{*}{$\begin{array}{l}\text { Mean CCT, } \\
\mu \mathrm{m}\end{array}$} & \multirow[t]{2}{*}{ SD } & \multirow{2}{*}{$\begin{array}{l}\text { Percentage of decrease } \\
\text { in mean CCT }\end{array}$} & \multicolumn{2}{|c|}{$95 \% \mathrm{Cl}$ for mean } & \multirow[t]{2}{*}{$P$-value* } \\
\hline & & & & & & Lower & Upper & \\
\hline $20-29$ years & 65 & 31.1 & 553.14 & 29.75 & - & 547.98 & 558.30 & - \\
\hline $30-39$ years & 37 & 17.7 & 550.86 & 27.99 & $0.002 \%$ & 544.38 & 557.35 & 0.988 \\
\hline $40-49$ years & 58 & 27.8 & 538.67 & 33.75 & $0.026 \%$ & 532.47 & 544.88 & 0.003 \\
\hline $50-59$ years & 23 & 11.0 & 537.39 & 35.75 & $0.028 \%$ & 526.78 & 548.01 & 0.031 \\
\hline$\geq 60$ years & 26 & 12.4 & 528.75 & 31.63 & $0.044 \%$ & 519.94 & 537.56 & $<0.001$ \\
\hline Total & 209 & 100 & 543.95 & 32.58 & $0.016 \%$ & 540.82 & 547.09 & $<0.001 * *$ \\
\hline
\end{tabular}

Notes: *Post-hoc test in comparison with first age group; **ANOVA.

Abbreviations: ANOVA, analysis of variance; $\mathrm{CCT}$, central corneal thickness; $\mathrm{Cl}$, confidence interval; SD, standard deviation.

Table 2 Descriptive statistics for CCT according to gender

\begin{tabular}{|c|c|c|c|c|c|c|c|}
\hline \multirow[t]{2}{*}{ Gender } & \multirow{2}{*}{$\begin{array}{l}\text { Number } \\
\text { of patients }\end{array}$} & \multirow[t]{2}{*}{$\%$} & \multirow{2}{*}{$\begin{array}{l}\text { Mean } \\
C C T\end{array}$} & \multirow[t]{2}{*}{ SD } & \multicolumn{2}{|c|}{$95 \% \mathrm{Cl}$ for mean } & \multirow[t]{2}{*}{$P$-value } \\
\hline & & & & & Lower & Upper & \\
\hline Male & 113 & 54.1 & 545.70 & 32.27 & $54 I .47$ & 549.93 & 0.235 \\
\hline Female & 96 & 45.9 & 541.90 & 32.91 & 537.22 & 546.59 & \\
\hline Total & 209 & 100 & 543.95 & 32.58 & 540.82 & 547.09 & \\
\hline
\end{tabular}

Abbreviations: $\mathrm{CCT}$, central corneal thickness; $\mathrm{Cl}$, confidence interval; SD, standard deviation. 


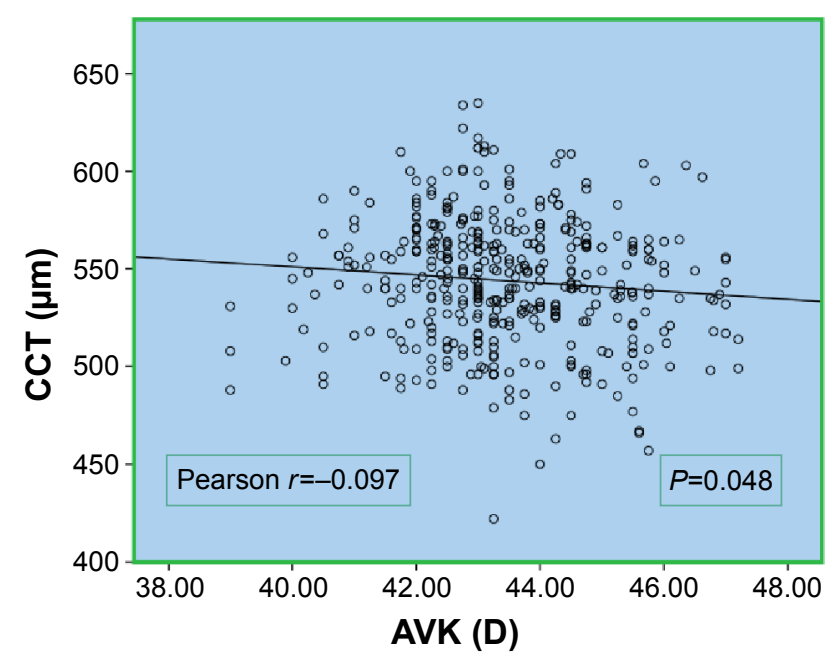

Figure 2 The correlation between CCT and AVK.

Abbreviations: AVK, average corneal curvature; CCT, central corneal thickness.

of intraocular pressure and glaucoma patient management ${ }^{17}$ and in prerefractive procedure assessment where knowledge of the corneal thickness is necessary for choosing the best treatment option and avoiding complications such as corneal ectasia. ${ }^{18}$

In this study, the mean CCT was $543.95 \pm 32.58 \mu \mathrm{m}$. This obtained value, in comparison to other studies that measured the CCT in Iraqi population is similar to that done in Baghdad by Ghazwan $(544.4 \pm 32.3 \mu \mathrm{m}),{ }^{19}$ and nearly similar to another study also in Baghdad by Riyam and Qasim $(541.25 \pm 34.96 \mu \mathrm{m}){ }^{20}$

The obtained CCT value, compared with the population of nearby countries, is lower than that of the study of the Turkish population $(552 \mu \mathrm{m})$ and Iranian population $(555.6 \mu \mathrm{m}){ }^{21,22}$ And it is similar to the study of the Saudi

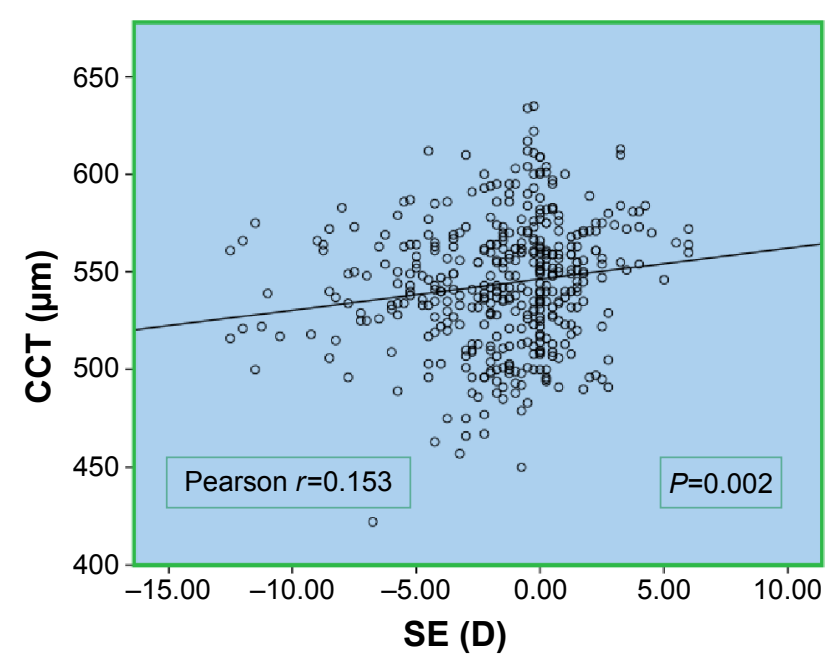

Figure 3 The correlation between CCT and SE. Abbreviations: CCT, central corneal thickness; SE, spherical equivalent. emmetropic population $(545.7 \mu \mathrm{m}){ }^{23}$ All the previous studies used ultrasonic pachymeter in the measurement of CCT.

Review of literatures indicates that there may be ethnicity-related differences in CCT throughout the world. Aghaian et $\mathrm{a}^{24}$ studied the corneal thickness by ultrasonic pachymeter in an ethnically diverse population of 801 eyes in a San Francisco glaucoma clinic. The mean CCT of all participants was $542.9 \mathrm{~mm}$. African Americans had the thinnest CCT $(521.0 \mathrm{~mm})$ of all races, including whites $(550.4 \mathrm{~mm})$ and Hispanics $(548.1 \mathrm{~mm})$. Among the Asian subpopulations, Japanese participants had the thinnest CCT $(531.7 \mathrm{~mm})$ compared with Chinese $(555.6 \mathrm{~mm})$ and Filipino (550.6 mm) subjects.

In our analysis of the relationship between age and CCT, we find a statistically significant negative association, several authors have reported a significant reduction of CCT with age. ${ }^{21,25-28}$ Hahn et al suggested that the decrease in density of keratocytes with age is responsible for the reduction of CCT values with age. ${ }^{29}$ Fewer studies did not find a statistically significant association between age and CCT. Gros-Otero et al who studied CCT in 375 eyes of Spanish population found a certain correlation between CCT and age, but it is so slight that these differences would be significant with a high number of patients. ${ }^{12}$ Similarly, Jonuscheit and Doughty found no age-related differences of CCT $(P=0.381)$ in 109 white European subjects. ${ }^{30}$

The association between CCT and gender has been analyzed in various studies in most of which, as in ours, statistically significant differences were not found. ${ }^{27,28,31-33}$ In contrast, some studies have found a statistical association between both factors, ${ }^{21,25,34}$ and in some cases there seems to be a certain degree of confusion when gender and age are analyzed jointly. ${ }^{21,25}$ Hahn et al found that the difference in CCT between the genders was only $4.6 \mu \mathrm{m}$, which is less than the mean interocular difference in CCT $(7.7 \mu \mathrm{m})$. They concluded that the difference between men and women CCT was statistically but not clinically significant. ${ }^{29}$

In studying the relationship between average corneal curvature and CCT, we find a statistically significant (weak) negative correlation (Pearson $r=-0.097, P=0.048$ ). There is controversy about the correlation between CCT and corneal curvature. Atsuo et al found a negative correlation between the two parameters in the Tajimi Study from Japan. ${ }^{35}$ Sawada et al reported a positive correlation in Japanese subjects aged 40 years or older. ${ }^{36}$ On the other hand, Chen et al found no significant correlations between the two parameters in normal Taiwanese Chinese adults, aged $40-80$ years (Pearson $r=0.013 ; P=0.770) .{ }^{37}$ 
Table 3 Descriptive statistics for CCT according to: (A) refraction major classes, (B) refraction subclasses

\begin{tabular}{|c|c|c|c|c|c|c|c|}
\hline & \multirow{2}{*}{$\begin{array}{l}\text { Number } \\
\text { of eyes }\end{array}$} & \multirow[t]{2}{*}{$\%$} & \multirow{2}{*}{$\begin{array}{l}\text { Mean } \\
\text { CCT }\end{array}$} & \multirow[t]{2}{*}{ SD } & \multicolumn{2}{|c|}{$95 \% \mathrm{Cl}$ for mean } & \multirow[t]{2}{*}{$P$-value* } \\
\hline & & & & & Lower & Upper & \\
\hline \multicolumn{8}{|l|}{ (A) Refraction major classes } \\
\hline Myopia & 239 & 57.2 & 539.05 & 33.68 & 534.75 & 543.34 & 0.019 \\
\hline Emmetropia & 77 & 18.4 & 550.47 & 33.45 & 542.88 & 558.06 & - \\
\hline Hypermetropia & 102 & 24.4 & 550.54 & 27.10 & 545.22 & 555.86 & 1.000 \\
\hline Total & 418 & 100 & 543.95 & 32.58 & 540.82 & 547.09 & $0.002 * *$ \\
\hline \multicolumn{8}{|l|}{ (B) Eye refraction subclasses } \\
\hline Severe myopia & 36 & 8.6 & 536.53 & 30.61 & 526.17 & 546.88 & 0.255 \\
\hline Moderate myopia & 74 & 17.7 & 540.22 & 31.42 & 532.94 & 547.49 & 0.357 \\
\hline Mild myopia & 129 & 30.9 & 539.08 & 35.88 & 532.83 & 545.33 & 0.132 \\
\hline Emmetropia & 77 & 18.4 & 550.47 & 33.45 & 542.88 & 558.06 & - \\
\hline Mild-moderate hypermetropia & 84 & 20.1 & 545.79 & 26.41 & 540.06 & 551.52 & 0.938 \\
\hline Moderate-severe hypermetropia & 18 & 4.3 & 572.72 & 18.09 & 563.73 & 581.72 & 0.084 \\
\hline Total & 418 & 100 & 543.95 & 32.58 & 540.82 & 547.09 & $<0.00 I^{* *}$ \\
\hline
\end{tabular}

Notes: *Post hoc test in comparison with emmetropia, **ANOVA.

Abbreviations: ANOVA, analysis of variance; CCT, central corneal thickness; Cl, confidence interval; SD, standard deviation.

Analysis of the relationship between refraction and CCT showed a statistically significant positive correlations between the two parameters (Pearson $r=0.153, P=0.002$ ). Further analysis of CCT level within refraction groups found significant difference between the whole myopic group and emmetropic group $(P=0.019)$. The effect of refractive status on CCT has been reported by many investigators. Von Bahr first generated interest in the correlation between myopia and CCT in 1956, when he reported thinner corneas in myopia $<-4 \mathrm{D} .^{38}$ There have been studies that have looked specifically at myopes and CCT. Chang et al studied corneal thickness in Taiwanese patients. The mean corneal thickness was $533 \pm 29 \mu \mathrm{m}$ and was thinner in more myopic eyes. They concluded that a decrease in corneal thickness was a result of a change in the anterior segment as the eyeball elongated in myopic progression. ${ }^{39}$

Similar relationship reported by Mohammed et al who found that CCT correlates with refractive error and myopes have the thinnest CCT $(449.65 \pm 39.27 \mu \mathrm{m})$, followed by emmetropes $(542.66 \pm 46.35 \mu \mathrm{m})$ and hyperopes $(557.67 \pm 41.83 \mu \mathrm{m}){ }^{40}$ This is consistent with the findings of Nemesure et al who found that CCT was directly related to refractive error. ${ }^{41}$ Price et al suggested that thin CCT

Table 4 The correlations between CCT and study variables

\begin{tabular}{lllll}
\hline Variable & Statistic type & Variable & & \\
\cline { 3 - 5 } & & Age (year) & AVK & SE \\
\hline CCT & Pearson correlation & -0.280 & -0.097 & 0.153 \\
& P-value & $<0.001$ & 0.048 & 0.002 \\
\hline
\end{tabular}

Note: If Pearson's correlation $>0$ then the correlation is positive, if $<0$ then it is negative.

Abbreviations: AVK, average corneal curvature; $C C T$, central corneal thickness; $\mathrm{SE}$, spherical equivalent. associated with myopic eyes may help to explain their increased susceptibility to glaucoma. ${ }^{42}$

In our study, no significant difference in the mean CCT was found when we compare each of the myopia subclassifications and emmetropia. Nemesure et al found that CCT was directly related to refractive errors, although no systemic alteration in CCT was found in myopia. ${ }^{41}$ Similarly, Pederson et al claimed that the process by which myopia progresses does not influence the CCT to a measurable degree. ${ }^{43}$

Other studies have found contradictory results. Price et al found no correlation between refraction and CCT. ${ }^{42}$ Similarly, Ortiz et al analyzed the relationship between the CCT and the degree of myopia in 175 myopic eyes. They did not find statistically significant differences in CCT between the myopic groups in their study. ${ }^{44}$ Liu and Pflugfelder found no correlation between CCT and the degree of myopia in corneal thickness in both contact lens wearers and nonwearers ${ }^{45}$ Pederson et al concluded that there was no statistical difference in CCT between emmetropes and myopes. ${ }^{43}$

Our data about refraction revealed that the SE correlates directly to the CCT when the analysis is performed for a large number of patients with wide range of refractive errors. This finding was also statistically significant when we compare myopic and emmetropic classes, where myopic patients had statistically significant thinner corneas than emmetropics.

\section{Conclusion}

In Iraqi population, the mean CCT was $543.95 \pm 32.58 \mu \mathrm{m}$ with a range of $422-636 \mu \mathrm{m}, \mathrm{CCT}$ not affected by gender. CCT 
significantly negatively correlated with age. CCT significantly positively correlated with refraction and myopics had significantly thinner cornea than emmetropics. There was a weak but significant negative correlation between CCT and corneal curvature.

\section{Recommendation}

We recommend taking in concern the decline in the CCT throughout life and the possibility of its decrease during myopic progression when we are planning for refractive surgeries and calculating the safe limits in corneal thickness.

Also, we recommend further studies about the relationship between CCT and other ocular parameters in Iraqi population such as the axial length.

\section{Disclosure}

The authors report no conflicts of interest in this work.

\section{References}

1. American Academy of Ophthalmology. Basic and Clinical Science Course. External Disease and Cornea, Section 8. San Francisco, CA: American Academy of Ophthalmology; 2015:6-21.

2. Bowling B. Kanski's Clinical Ophthalmology: A Systemic Approach. 8th ed. China: Elsevier; 2016:168.

3. Dua HS, Faraj LA, Said DG, Gray T, Lowe J. Human corneal anatomy redefined: a novel pre-Descemet's layer (Dua's layer). Ophthalmology. 2013;120(9):1778-1785.

4. Yanoff M, Duker JS. Cornea and ocular surface diseases. In: Ayad A Farjo, Matthew V Brumm, H Kaz Soong, Mohsin Ali, Jerome C Ramos-Esteban, L Jay Katz, editors. Ophthalmology. 4th ed. China: Elsevier Saunders; 2014:163-165.

5. Yanoff M, Duker JS. Glaucoma. In: Ayad A Farjo, Matthew V Brumm, H Kaz Soong, Mohsin Ali, Jerome C Ramos-Esteban, L Jay Katz, editors. Ophthalmology. 4th ed. China: Elsevier Saunders; 2014:1020.

6. Tasman W, Jaeger EA, editors. Cornea. Duane's Ophthalmology. 13th Ed. Philadelphia: Lippincott Williams \& Wilkins; 2012:12365-12368.

7. Ehlers N, Bramsen T, Sperling S. Applanation tonometry and central corneal thickness. Acta Ophthalmol (Copenh). 1975;53(1): $34-43$.

8. Kiely PM, Carney LG, Smith G. Diurnal variations of corneal topography and thickness. Am J Optom Physiol Opt. 1982;59(12): 976-982.

9. Singh RP, Goldberg I, Graham SL, Sharma A, Mohsin M. Central corneal thickness, tonometry, and ocular dimensions in glaucoma and ocular hypertension. J Glaucoma. 2001;10(3):206-210.

10. Gordon MO, Beiser JA, Brandt JD, et al. The Ocular Hypertension Treatment Study: baseline factors that predict the onset of primary open-angle glaucoma. Arch Ophthalmol. 2002;120(6):714-720.

11. Damji KF, Muni RH, Munger RM. Influence of corneal variables on accuracy of intraocular pressure measurement. J Glaucoma. 2003;12(1) $69-80$.

12. Gros-Otero J, Arruabarrena-Sánchez C, Teus M. Central corneal thickness in a healthy Spanish population. Arch Soc Esp Oftalmol. 2011; 86(3):73-76.

13. Swartz T, Marten L, Wang M. Measuring the cornea: the latest developments in corneal topography. Curr Opin Ophthalmol. 2007;18(4) 325-333.

14. Wang Z, Chen J, Yang B. Posterior corneal surface topographic changes after laser in situ keratomileusis are related to residual corneal bed thickness. Ophthalmology. 1999;4(2):406-409.
15. Huang J, Lu W, Savini G, et al. Evaluation of corneal thickness using a Scheimpflug-Placido disk corneal analyzer and comparison with ultrasound pachymetry in eyes after laser in situ keratomileusis. J Cataract Refract Surg. 2013;39(7):1074-1080.

16. Sunita A, Athiya A, David J Apple, Lucio B, Jorge LA, Suresh KP, Amar A, editors. Textbook of Ophthalmology. Vol. 2. New Delhi: Jaypee Brothers; 2002:114-983.

17. Shah S. Accurate intraocular pressure measurement: the myth of modern ophthalmology. Ophthalmology. 2000;107(10):1805-1807.

18. Hashemi H, Mehravaran S. Central corneal thickness measurement with Pentacam, Orbscan II, and ultrasound devices before and after laser refractive surgery for myopia. J Cataract Refract Surg. 2007;33(10): $1701-1707$.

19. Alwan GH. Mean central corneal thickness in a sample of non-glaucomatous Iraqi population [dissertation]. Baghdad: Scientific Council of Ophthalmology; 2011.

20. Riyam FR, Farhood QK. Measurement of central corneal thickness by ultrasonic pachymeter and oculus pentacam in patients with well-controlled glaucoma: hospital-based comparative study. Clin Ophthalmol. 2016;10:359-364.

21. Altinok A, Sen E, Yazici A, Aksakal FN, Oncul H, Koklu G. Factors influencing central corneal thickness in a Turkish population. Curr Eye Res. 2007;32(5):413-419.

22. Hashemi H, Yazdani K, Mehravaran S, et al. Corneal thickness in a population-based, cross-sectional study: the Tehran Eye Study. Cornea. 2009;28(4):395-400.

23. Al-Mezaine HS, Al-Obeidan Saleh, Kangave D, Sadaawy A, Wehaib TA, Al-Amro SA. The relationship between central corneal thickness and degree of myopia among Saudi adults. Int Ophthalmol. 2009;29(5): 373-378.

24. Aghaian E, Choe JE, Lin S, Stamper RL. Central corneal thickness of Caucasians, Chinese, Hispanics, Filipinos, African Americans, and Japanese in a glaucoma clinic. Ophthalmology. 2004;111(12):2211-2219.

25. Li P, Hu Y, Xu Q, Zhang G, Mai C. Central corneal thickness in adult Chinese. J Huazhong Univ Sci Technolog Med Sci. 2006;26(1): 141-144.

26. Cho P, Lam C. Factors affecting the central corneal thickness of Hong Kong-Chinese. Curr Eye Res. 1999;18(5):368-374.

27. Lam AK, Douthwaite WA. The corneal-thickness profile in Hong Kong Chinese. Cornea. 1998;17(4):384-388.

28. Lekskul M, Aimpun P, Nawanopparatskul B, et al. The correlations between central corneal thickness and age, gender, intraocular pressure and refractive error of aged 12-60 years old in rural Thai community. J Med Assoc Thai. 2005;88 (Suppl 3):S175-S179.

29. Hahn S, Azen S, Ying-Lai M, Varma R; Los Angeles Latino Eye Study Group. Central corneal thickness in Latinos. Inv Ophthalmol Vis Sci. 2003;44(4):1508-1512.

30. Jonuscheit S, Doughty MJ. Evidence for a relative thinning of the peripheral cornea with age in white European subjects. Invest Ophthalmol Vis Sci. 2009;50(9):4121-4128.

31. Lifshitz T, Levy J, Rosen S, Belfair N, Levinger S. Central corneal thickness and its relationship to the patient's origin. Eye. 2006;20(4): 460-465.

32. Haider KM, Mickler C, Oliver D, Moya FJ, Cruz OA, Davitt BV. Age and racial variation in central corneal thickness of preschool and schoolaged children. J Pediatr Ophthalmol Strabismus. 2008;45(4):227-233.

33. Ashwin PT, Shah S, Pushpoth S, Wehbeh L, Ilango B. The relationship of central corneal thickness (CCT) to thinnest central cornea (TCC) in healthy adults. Cont Lens Anterior Eye. 2009;32(2):64-67.

34. Durkin SR, Tan EWH, Casson RJ, Selva D, Newland HS. Central corneal thickness among Aboriginal people attending eye clinics in remote South Australia. Clin Exp Ophthalmol. 2007;35(8):728-732.

35. Tomidokoro A, Araie M, Iwase A; Tajimi Study Group. Corneal thickness and relating factors in a population-based study in Japan: the Tajimi Study. AmJ Ophthalmol. 2007;144(1):152-154.

36. Sawada A, Tomidokoro A, Araie M, Iwase A, Yamamoto T. Refractive errors in an elderly Japanese population: the infection after LASIK. Ophthalmology. 2003;110:276-285. 
37. Chen MJ, Liu YT, Tsai CC, Chen YC, Chou CK, Lee SM. Relationship between central corneal thickness, refractive error, corneal curvature, anterior chamber depth and axial length. J Chin Med Assoc. 2009;72(3): 133-137.

38. von Bahr G. Corneal thickness: its measurement and changes. Am J Ophthalmol. 1956;42(2):251-266.

39. Chang SW, Tsai IL, Hu FR, Lin LL, Shih YF. The cornea in young myopic adults. Br J Ophthalmol. 2001;85(8):916-920.

40. Mohamed NY, Hassan MN, Ali NA, Binnawi KH. Central corneal thickness in Sudanese population. Sud J Ophthalmol. 2009;1(1):29-32.

41. Nemesure B, Wu SY, Hennis A, Leske MC; Barbados Eye Study Group. Corneal thickness and intraocular pressure in the Barbados eye studies. Arch Ophthalmol. 2003;121(2):240-244.
42. Price FW Jr, Koller DL, Price MD. Central corneal thickness in patients undergoing laser in situ keratomileusis. Ophthalmology. 1999; 106(11):2216-2220.

43. Pedersen L, Hjortdal J, Ehlers N. Central corneal thickness in high myopia. Acta Ophthalmologica Scand. 2005;83(5):539-541.

44. Ortiz S, Mena L, Rio-San Cristobala A, Martin R. Relationships between central and peripheral corneal thickness indifferent degrees of myopia. J Optom. 2014;7(1):44-50.

45. Liu Z, Pflugfelder SC. The effects of long-term contact lens wear on corneal thickness, curvature, and surface regularity. Ophthalmology. 2000;107(1):105-111.
Clinical Ophthalmology

\section{Publish your work in this journal}

Clinical Ophthalmology is an international, peer-reviewed journal covering all subspecialties within ophthalmology. Key topics include: Optometry; Visual science; Pharmacology and drug therapy in eye diseases; Basic Sciences; Primary and Secondary eye care; Patient Safety and Quality of Care Improvements. This journal is indexed on

\section{Dovepress}

PubMed Central and CAS, and is the official journal of The Society of Clinical Ophthalmology (SCO). The manuscript management system is completely online and includes a very quick and fair peer-review system, which is all easy to use. Visit http://www.dovepress.com/ testimonials.php to read real quotes from published authors. 